\title{
Clinical and medication profiles stratified by household income in patients referred for diabetes care Doreen M Rabi ${ }^{1,2,3}$, Alun L Edwards ${ }^{1}$, Lawrence W Svenson ${ }^{5}$, Peter M Sargious ${ }^{1}$, Peter Norton ${ }^{4}$, Erik T Larsen ${ }^{6}$ and William A Ghali*1,2,3
}

\author{
Address: ${ }^{1}$ Department of Medicine, University of Calgary, Calgary, Canada, ${ }^{2}$ Department of Community Health Sciences, University of Calgary, \\ Calgary, Canada, ${ }^{3}$ Centre for Health and Policy Studies, University of Calgary, Calgary, Canada, ${ }^{4}$ Department of Family Medicine, University of \\ Calgary, Calgary, Canada, ${ }^{5}$ Alberta Health and Wellness, Edmonton, Canada and ${ }^{6}$ Calgary Laboratory Services, Calgary, Canada \\ Email: Doreen M Rabi - doreen.rabi@calgaryhealthregion.ca; Alun L Edwards - aedwards@ucalgary.ca; \\ Lawrence W Svenson - larry.svenson@gov.ab.ca; Peter M Sargious - peter.sargious@calgaryhealthregion.ca; Peter Norton - norton@ucalgary.ca; \\ Erik T Larsen - erik.larsen@cls.ab.ca; William A Ghali* - wghali@ucalgary.ca \\ * Corresponding author
}

Published: 30 March 2007

Cardiovascular Diabetology 2007, 6:11 doi:10.1186/1475-2840-6-1I
Received: 2 January 2007

Accepted: 30 March 2007

This article is available from: http://www.cardiab.com/content/6/I/II

(C) 2007 Rabi et al; licensee BioMed Central Ltd.

This is an Open Access article distributed under the terms of the Creative Commons Attribution License (http://creativecommons.org/licenses/by/2.0), which permits unrestricted use, distribution, and reproduction in any medium, provided the original work is properly cited.

\begin{abstract}
Background: Low income individuals with diabetes are at particularly high risk for poor health outcomes. While specialized diabetes care may help reduce this risk, it is not currently known whether there are significant clinical differences across income groups at the time of referral. The objective of this study is to determine if the clinical profiles and medication use of patients referred for diabetes care differ across income quintiles.

Methods: This cross-sectional study was conducted using a Canadian, urban, Diabetes Education Centre (DEC) database. Clinical information on the 4687 patients referred to the DEC from May 2000 - January 2002 was examined. These data were merged with 200I Canadian census data on income. Potential differences in continuous clinical parameters across income quintiles were examined using regression models. Differences in medication use were examined using Chi square analyses.

Results: Multivariate regression analysis indicated that income was negatively associated with BMI $(p<0.0005)$ and age $(p=0.023)$ at time of referral. The highest income quintiles were found to have lower serum triglycerides $(p=0.0 \mathrm{II})$ and higher HDL-c $(p=0.008)$ at time of referral. No significant differences were found in HBAIC, LDL-c or duration of diabetes. The Chi square analysis of medication use revealed that despite no significant differences in HBAIC, the lowest income quintiles used more metformin $(p=0.00 \mathrm{I})$ and sulfonylureas $(p<0.0005)$ than the wealthy. Use of other therapies were similar across income groups, including lipid lowering medications. High income patients were more likely to be treated with diet alone $(p<0.0005)$.

Conclusion: Our findings demonstrate that low income patients present to diabetes clinic older, heavier and with a more atherogenic lipid profile than do high income patients. Overall medication use was higher among the lower income group suggesting that differences in clinical profiles are not the result of under-treatment, thus invoking lifestyle factors as potential contributors to these findings.
\end{abstract}




\section{Background}

Individuals with low income are at increased risk for the development of diabetes [1-3] Low income is also an independent predictor of hospitalization for the acute complications of diabetes and is associated with higher odds of microvasculopathy and heart disease [4-6].

There is an extensive literature that explores the association between income and health outcomes among the general population. The relationship between income and health outcomes is complex and is mediated by a number of factors. Potential mediating factors include differential access to care [7-10], behavioural and psycho-social factors [11-16], and biologic factors [17-19]. Several researchers have shown, that even within universal health care systems, the poor are less effective at accessing specialty care $[7-10,20]$. They are also more likely to partake in poor health-related behaviours (such as smoking, consuming diets low in fruits and vegetables, and sedentary lifestyles [20-23]) and are more likely to be overweight or obese $[22,24,25]$. Biologic differences among income groups have also been identified. High income groups are more likely to have higher levels of HDL cholesterol and low income groups have been found to have subtle changes in their neuro-endocrine and immune responses that may predispose them to atherosclerosis $[17-19,26]$.

Low income patients with diabetes are at greater risk for adverse health outcomes but the factors influencing this relationship are unclear. There is emerging evidence that income does not appear to effect access to specialty diabetes care $[27,28]$, but little is known about clinical, behavioural or biologic differences across income groups, among those with diabetes.

In recognizing our incomplete understanding of the income relationship to diabetes, this study proposed to explore whether there are clinical and/or biologic differences across income groupings among patients referred to an urban diabetes education centre (DEC). The study's objectives specifically included an assessment of the clinical profiles (including medication use) of patients across income groupings at the time of referral for specialized diabetes care.

\section{Methods}

\section{Data Sources}

To conduct this work, we used a regional DEC database that captures basic demographic information on all attendees to the regional clinic situated in Calgary, Alberta, a large Canadian city. The sampling frame was all active patients at the DEC from May 1, 2000 to January 9, 2002. The sample consisted of 4687 patients. All patients included were from a single health region within the province of Alberta. This DEC is the single regional provider of diabetes education services. Access is dependent upon physician referral to the centre. The postal codes of patients registered in the DEC database were linked to their corresponding dissemination area (DA) using the Statistics Canada Postal Code Conversion File (PCCF).

Neighborhood income data were obtained from Statistics Canada Census data (2001). We defined a neighborhood as equivalent to a census dissemination area (DA)- a small geographic area covered by a single census data collector which typically contains 400-700 persons. Therefore, median household income per DA was the income measure used in this study. These data were merged with the DEC database on the variable DA. Neighbourhood income has been shown to be reasonably concordant with individual income in urban settings $[29,30]$. There is also increasing evidence that neighbourhood income is valid SES construct that predicts health outcomes independently of individual income [31,32].

\section{Derivation of Income Quintiles}

Household income quintiles were generated from DA annual income data. All income data is reported in Canadian dollars. The size and associated incomes for the income quintiles were as follows:

1) Income quintile $1, n=940$, less than $\$ 40877$

2) Income quintile $2, \mathrm{n}=937, \$ 40878-\$ 53065$

3) Income quintile 3, $\mathrm{n}=936, \$ 53066-\$ 62921$

4) Income quintile 4, n = 938, \$62922 - 79828

5) Income quintile 5, $(n=936)$, more than $\$ 79829$

\section{Study Variables and Statistical Analyses}

Physicians referring patients to the DEC complete a standardized referral form that includes clinical data. This information was then entered into the DEC patient registry. Clinical information examined in this study included: serum hemoglobin A1C (HBA1C); serum lipid profiles including levels of low density lipoprotein (LDL-C), high density lipoprotein (HDL-c) and triglyceride; microalbumin to creatinine ratios and medications used at time of referral. Height and weight are measured upon presentation to clinic; these measures were used to calculate the body mass index (BMI) which was then entered into the DEC database.

Potential differences in continuous clinical parameters across income quintiles were examined using regression models. If inspection of the distribution of these variables suggested a linear relationship between income and the variable of interest, then income quintile was modeled as 
a single ordinally-coded predictor variable. If, on the other hand, the relationship was not linear, then regression was performed using dummy variables for each income quintile relative to the lowest income quintile as a reference group. Covariates considered in these models included sex and medication use. Differences in categorically-coded medication use across income quintiles, meanwhile, were examined using Chi square analyses. All statistical analyses were performed in STATA, version 8 .

\section{Results}

\section{Descriptive Analysis}

Clinical characteristics of patients referred for diabetes care and education are listed, by income quintile, in Table 1. The median age of patients increased as income level decreased. The median age in the highest income groups (quintile 5) was 55.3 years compared to the lowest income group (quintile 1) which was almost 2 years older at time of referral with a median age of 57.0 years. There was a similar inverse relationship between income level and BMI. The median BMI in the wealthiest quintile (quintile 5) was 28 compared median BMIs of 29.6 in quintile 1 and 29.8 in quintile 2. Our results also indicate that the lowest income quintile presents to clinic later from the time of diagnosis of diabetes. The median duration of diabetes was 4 years in the lowest quintile, compared to 3 years in all of the other quintiles. In terms of diabetes-related clinical parameters, patients did not differ significantly across groups with respect to serum LDLc levels. Patients in the highest income quintile had the highest HDL-c. An inverse relationship between income and triglycerides is suggested as the median triglyceride levels range from $2.40 \mathrm{mmol} / \mathrm{L}$ in the lowest income group down to $2.12 \mathrm{mmol} / \mathrm{L}$ in the highest income group. Glycemic control appears to be slightly better in the highest income group as evidenced by a median HBA1C of $8.4 \%$ in quintile 5 compared to a median HBA1C of $8.9 \%$ in all other income groups. There is also a suggestion of a negative association between microalbumin creatinine ratio $(\mathrm{M}: \mathrm{C})$ and income. The lowest income group had a median M:C of 2.3 compared to a median $\mathrm{M}: \mathrm{C}$ of 1.5 in the highest income group. Boxplots illustrating the distribution of clinical characteristics are illustrated in figure 1.

\section{Regression Analysis \\ Clinical profiles}

Visual inspection of the distribution of the variables age, body mass index (BMI), and duration of diabetes (Figure 1 , panels $\mathrm{a}, \mathrm{b}$ and $\mathrm{c}$ ), suggested a linear relationship between those clinical characteristics and income. Linear regression on ordinally coded income groupings was thus performed (see Table 2) and indeed demonstrated a significant negative association between age at the time of referral and median household income per DA ( $\beta$-coefficient $=-.339,95 \%$ CI $-0.65--0.03)$. A similar negative association was noted between BMI and income where the $\beta$-coefficient was found to be -.362 (95\% CI -0.51 - 0.21 ). This relationship remained significant even after controlling for age and diabetes medication use. These findings reveal that wealthy patients presenting for diabetes education are younger and leaner than those from lower income groups. While this might suggest that the wealthy are presenting earlier in the course of their diabetes, we found no significant association between income and the duration of diabetes ( $\beta$-coefficient $=-.0167,95 \%$ CI -1.32 - 1.29).

Visual inspection of the distribution on the clinical variables of LDL-c, HDL-c, triglycerides, HBA1C and microalbumin:creatinine ratio did not reveal an obvious linear relationship in the associations with income (Figure 1, panels d-h). In this instance, regression modeling was done by comparing each individual income quintile to a pre-defined reference group, income quintile 1. Table 3 lists the results of the analysis. No significant association was found between income and level of glycemic control as measured by HBA1C. After controlling for age, sex, and differences in the use of anti-diabetic medications, the highest income quintile had a trend towards a lower HBA1C. Similarly, while no significant association was found with respect to microalbumin:creatinine ratio, the box plot of this variable (Figure 1, panel h) suggests that the highest income groups have lower ratios.

The association of serum lipid levels at the time of referral was also examined. While no relationship was found between the levels of LDL-c and income quintile, significant findings were noted with respect to HDL-c and triglyceride levels. In the unadjusted analysis, HDL-c was highest in the wealthiest income quintile but this did not reach statistical significance. After adjusting for differences in sex, age and use of lipid lowering medications, the association strengthened and became significant. Triglyceride levels were similarly lowest in the highest income group, and this was significant both in the unadjusted and adjusted analyses (Table 3 ).

\section{Medication Use}

The proportions of patients, by income quintile, prescribed specific medications are presented in Table 4. Chi square analyses indicate socio-economic gradients for the use of certain diabetes therapies. A statistically significant gradient was noted for the use of diet alone to manage diabetes. In the lowest income quintile, $14.4 \%$ of patients presented on diet alone, compared to $24.4 \%$ in the highest income group $\left(\chi^{2}=44.22, p<0.0005\right)$. An inverse gradient was noted in the use of oral diabetes medications. Metformin was used by $37.3 \%$ of patients in the lowest income group, compared to $30 \%$ in the highest income group $\left(\chi^{2}=18.85, \mathrm{p}=0.001\right)$. Sulfonylureas were also 
Table I: Clinical Profiles at time of referral by income quintile

\begin{tabular}{|c|c|c|c|c|c|c|}
\hline & \multicolumn{6}{|c|}{ Income Quintile } \\
\hline & I (low) & 2 & 3 & 4 & 5 (high) & $p$-for trend* \\
\hline Clinical Characteristic & \multicolumn{6}{|c|}{ Median (IQR) } \\
\hline Age (in years) & $56.95(22.9)$ & $56.52(21.48)$ & $56.95(19.94)$ & $55.24(19.44)$ & $55.27(18.5)$ & 0.032 \\
\hline BMI & $29.6(8.6)$ & $29.8(8.3)$ & $29(7.9)$ & $29.5(8.2)$ & $28(7.2)$ & $<0.0005$ \\
\hline Duration of Diabetes (in years) & $4(9)$ & $3(8)$ & $3(10)$ & $3(9)$ & $3(7)$ & 0.98 \\
\hline LDL-c (mmol/L) & $3.01(1.26)$ & $2.97(1.1)$ & $3.02(1.22)$ & $2.97(1.23)$ & $2.99(1.26)$ & ** \\
\hline $\mathrm{HDL}-\mathrm{c}(\mathrm{mmol} / \mathrm{L})$ & $1.12(0.41)$ & I.I (0.36) & $1.09(0.37)$ & I.I (0.36) & $1.15(0.35)$ & $* *$ \\
\hline Triglycerides (mmol/L) & $2.40(1.88)$ & $2.29(1.99)$ & $2.41(2.0)$ & $2.32(1.76)$ & $2.12(1.61)$ & $* *$ \\
\hline HBAIC (\%) & $8.9(3.7)$ & $8.9(3.7)$ & $8.9(3.5)$ & $8.9(3.7)$ & $8.4(3.3)$ & ** \\
\hline Microalbumin: Creatinine & $2.3(9)$ & $1.95(7.7)$ & $2.4(7.1)$ & $1.6(5.9)$ & $1.5(5)$ & *** \\
\hline
\end{tabular}

*results of univariate analyses for trend when income could be modeled as a single, ordinally-coded variable

**these variables did not have a simple linear relationship with income (results of regression models where income quintiles are modeled as dummy variables are displayed in Table 3).

more commonly used in the lower income quintiles compared to the highest income quintiles $\left(\chi^{2}=25.63, \mathrm{p}<\right.$ $0.0005)$. No significant differences were found across income quintiles in the use of glucosidase inhibitors $\left(\chi^{2}=\right.$ 2.99, $\mathrm{p}=0.558)$, thiazolideindiones (TZD) $\left(\chi^{2}=2.93, \mathrm{p}=\right.$ $0.087)$ or subcutaneous insulin $\left(\chi^{2}=2.56, \mathrm{p}=0.392\right)$.

\section{Discussion}

Individuals with low income and diabetes are at increased risk for developing vascular complications. While the processes mediating this low income/poor health outcome relationship have been examined in the general population, little is known about the factors mediating this relationship among those with diabetes. Previous research has shown that access to specialty diabetes care appears equitable across income groups $[27,28]$, suggesting that differences in health outcomes may be mediated by other factors.

\section{Clinical and Biologic Factors}

This study demonstrates that there are clinically significant differences in some biologic parameters across income quintiles and that low income patients present to clinic with higher risk profiles. Low-income patients are older at time of referral and have more atherogenic metabolic profiles with higher serum triglycerides and lower HDL levels, which are associated with a higher risk for developing cardiovascular disease [33-35]. While a significant association between income and HBA1C was not noted, inspection of the distribution of HBA1C suggests a trend towards a lower HBA1C in the highest income quintile.

This study also suggests that differences in metabolic status are not due to overt under-treatment of the economi- cally disadvantaged. The lowest income groups were using more sulfonylureas and metformin compared to the wealthiest groups. Even the use of more costly therapies such as TZD and lipid-lowering therapies were similar across income groups.

\section{Behavioural Factors}

This study also provides some insight into potential health related behavioural differences across income groups. It has been shown in previous research that sedentary lifestyles are more common among lower income populations. In this study, the lower income groups had the highest BMIs. This raises the possibility that the lower income groups are less physically active than their wealthy counterparts. The lower HDL levels and higher triglycerides might also reflect behavioural differences with respect to diet and/or exercise [36]. Unfortunately, the data set used in this study does not contain detailed data on diet or exercise so we were unable to explicitly assess differences in these important behaviours.

\section{Other considerations}

High income is frequently associated with higher health literacy and a greater ability to apply health-related knowledge $[37,38]$. It should be noted that while we did not find that HBA1Cs differ significantly at the time of referral, others have documented that individuals from higher socio-economic strata are more likely to experience significant lowering of their HBA1Cs after assessment at diabetes clinic $[37,38]$. It would be most interesting to know had the clinical profiles of these patients been reevaluated 1 year following their referral whether the differences noted would have remained the same, been attenuated or perhaps been even more pronounced due to differences in health literacy. 
A- Age at Referral

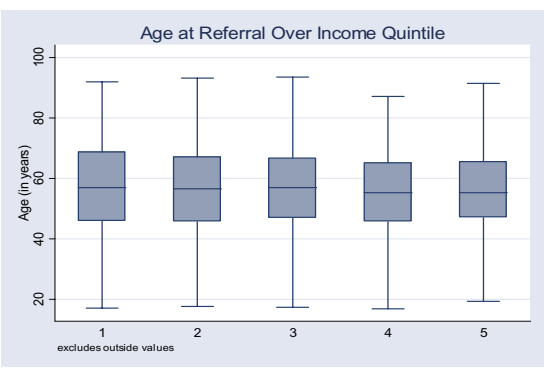

D - Hemoglobin A1C

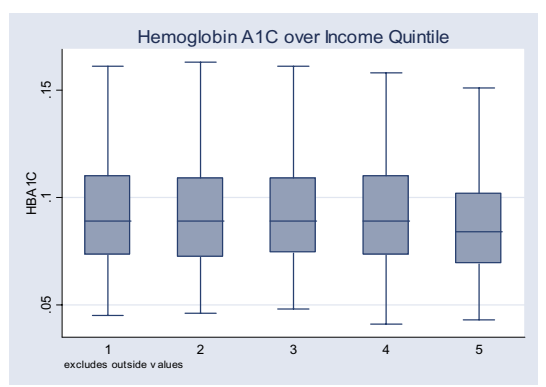

G- Triglycerides

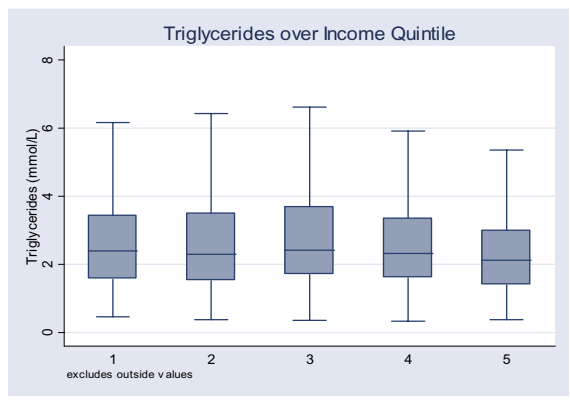

B - BMI

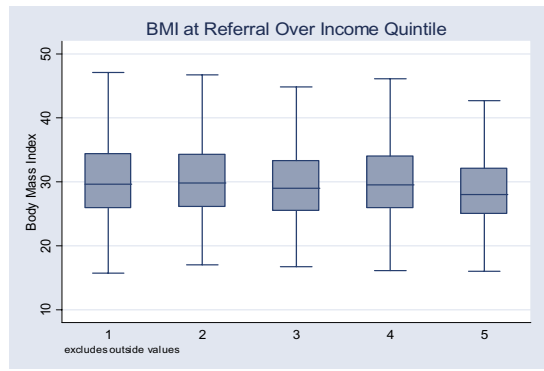

E - LDL Cholesterol

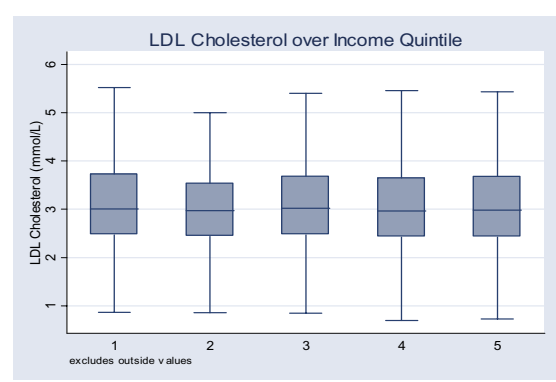

H- Microalbumin: Creatinine Ratio

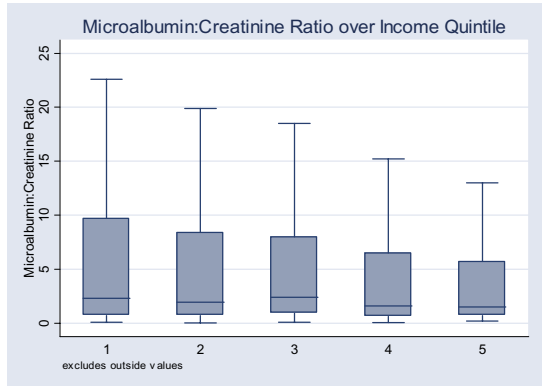

C - Duration of Diabetes

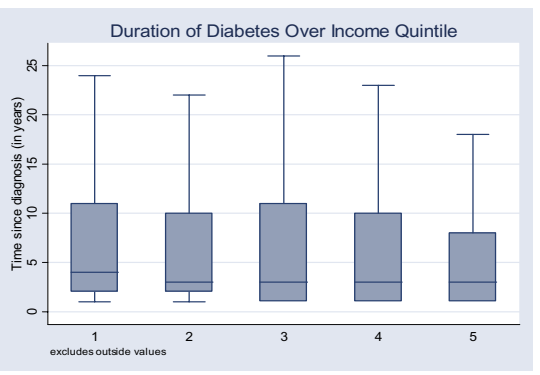

F - HDL Cholesterol

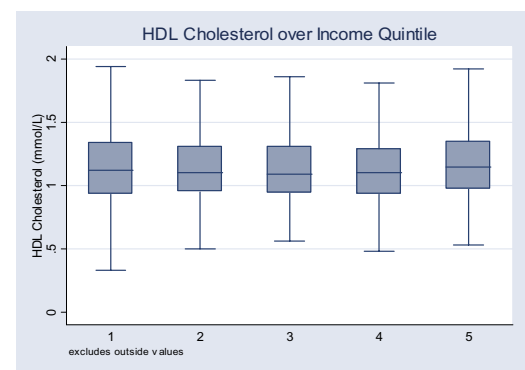

\section{Figure I}

Distribution of clinical variables across income quintiles.

While we did not find a significant difference with respect to the duration of the diagnosis of diabetes at the time of referral, examination of the distribution of this variable certainly suggests that this may, in part, be mediating some of clinical differences noted. The wealthiest patient group was also younger, and more likely to be controlled with diet alone, suggesting that these patients may be presenting at an earlier point in the natural history of their diabetes. If wealthy patients were being referred earlier (perhaps due to earlier diagnosis), this may also help explain the inverse relationship between income and complication risk. As there is now clear evidence that aggressive management of blood glucose, high blood pressure and high serum lipids will effectively prevent the micro- and macrovascular complications of diabetes [39-

Table 2: Association of Income Quintile with General Clinical Parameters

\begin{tabular}{lcccc}
\hline Clinical Characteristic & Co-variate & B-coefficient (p-value) & $\begin{array}{c}\text { B-coefficient - adjusted for sex } \\
(\mathbf{p}-\text {-value })\end{array}$ & $\begin{array}{c}\text { B-coefficient - adjusted for sex, } \\
\text { age \& therapy (p-value) }\end{array}$ \\
\hline Age & Quintile & $-.339(0.032)$ & $-.361(0.023)$ & $-.306(<0.0005)$ \\
BMI & Quintile & $-.362(<0.0005)$ & $-.319(<0.0005)$ & $.0272(0.968)$ \\
Duration of DM & Quintile & $-.0167(0.980)$ & $.025)$ \\
\hline
\end{tabular}


Table 3: Association of Income Quintile with Diabetes-related Clinical Parameters

\begin{tabular}{|c|c|c|c|}
\hline Clinical Parameter & Income Quintile & B-coefficient - Unadjusted ( $p$-value) & B-coefficient - Adjusted ( $p$-value)* \\
\hline \multirow[t]{5}{*}{ HDL-C } & I (reference) & & \\
\hline & 2 & $.0126(0.798)$ & $.015(0.76)$ \\
\hline & 3 & $.0625(0.201)$ & $.063(0.20)$ \\
\hline & 4 & .0151 (0.757) & $.021(0.67)$ \\
\hline & 5 & $.0756(0.120)$ & $.084(0.09)$ \\
\hline \multirow[t]{5}{*}{ LDL-c } & I (reference) & & \\
\hline & 2 & $-.0813(0.222)$ & $-.086(0.193)$ \\
\hline & 3 & $-.010(0.885)$ & $-.016(0.805)$ \\
\hline & 4 & $-.0391(0.540)$ & $-.044(0.488)$ \\
\hline & 5 & $-.022(0.73 \mathrm{I})$ & $-.025(0.691)$ \\
\hline \multirow[t]{5}{*}{ HDL-c } & I (reference) & & \\
\hline & 2 & $-.013(0.52)$ & $-.01(0.6)$ \\
\hline & 3 & $-.018(0.35)$ & $-.009(0.64)$ \\
\hline & 4 & $-.014(0.46)$ & $-.001(0.95)$ \\
\hline & 5 & $.031(0.11)$ & $.05(0.008)$ \\
\hline \multirow[t]{5}{*}{ Triglycerides } & I (reference) & & \\
\hline & 2 & $-.23(0.40)$ & $-.22(0.43)$ \\
\hline & 3 & $-.05(0.86)$ & $-.06(0.84)$ \\
\hline & 4 & $-.26(0.34)$ & $-.28(0.3 \mathrm{I})$ \\
\hline & 5 & $-.63(0.019)$ & $-.68(0.011)$ \\
\hline \multirow[t]{5}{*}{ Microalbumin: Creatinine } & I (reference) & & \\
\hline & 2 & -8.560 .058 & $-8.97(0.047)$ \\
\hline & 3 & -2.880 .540 & $-2.43(0.602)$ \\
\hline & 4 & -7.580 .097 & $-7.16(0.116)$ \\
\hline & 5 & -6.990 .122 & $-7.01(0.119)$ \\
\hline
\end{tabular}

*Adjusted for age, sex, and therapy (HBAIC was adjusted for anti-hyperglycemic medication use, LDL-c, HDL-c and Triglycerides were adjusted for lipid-lowering therapy use and Microalbumin: creatinine was adjusted for anti-hypertensive medication use.)

43], it follows that the earlier a specialist intervenes, the more effective these prevention strategies might be.

This study has limitations. This is a cross sectional study that examined the clinical profiles of patients at one point in time. These referrals were not necessarily index referral, and had we compared clinical profiles at first contact with specialty care, it is possible that some of the clinical differences noted may have been attenuated. It is noteworthy that clinical data were entered into the DEC database from a standardized clinic referral form. All clinical data examined in this study, therefore, were provided by the referring physician. If doctors differ in the manner in which they complete, or do not complete this form, an informa-

Table 4: Association of Income with Medical Therapy Use

\begin{tabular}{|c|c|c|c|c|c|c|}
\hline & \multicolumn{5}{|c|}{ Income Quintile } & \multirow[t]{2}{*}{$P$-value } \\
\hline & I (low) & 2 & 3 & 4 & 5 (high) & \\
\hline \multicolumn{7}{|l|}{ Therapy } \\
\hline Diet Only & $14.1 \%$ & $14.4 \%$ & $16.9 \%$ & $18.8 \%$ & $24.4 \%$ & $<0.0005$ \\
\hline Metformin & $37.3 \%$ & $36.1 \%$ & $37.0 \%$ & $31.5 \%$ & $30.0 \%$ & 0.001 \\
\hline Sulfonylureas & $29.6 \%$ & $30.1 \%$ & $29.3 \%$ & $24.1 \%$ & $22.4 \%$ & $<0.0005$ \\
\hline $\begin{array}{l}\text { Glucosidase } \\
\text { Inhibitors }\end{array}$ & $2.0 \%$ & $1.3 \%$ & $1.8 \%$ & $2.0 \%$ & $1.2 \%$ & 0.558 \\
\hline TZD & $3.9 \%$ & $3.5 \%$ & $4.1 \%$ & $4.2 \%$ & $3.5 \%$ & 0.886 \\
\hline Insulin & $19.8 \%$ & $18.2 \%$ & $18.3 \%$ & $18.6 \%$ & $17.2 \%$ & 0.688 \\
\hline $\begin{array}{l}\text { Lipid Lowering } \\
\text { Medication }\end{array}$ & $11.8 \%$ & $9.0 \%$ & $9.3 \%$ & $9.6 \%$ & $11.0 \%$ & 0.212 \\
\hline $\begin{array}{c}\text { Anti-Hypertensive } \\
\text { Medication }\end{array}$ & $19.7 \%$ & $21.7 \%$ & $19.0 \%$ & $19.7 \%$ & $19.0 \%$ & 0.596 \\
\hline
\end{tabular}


tion bias could be introduced to this study. We do not have any evidence, however, that physicians' documentation skills should differ based on the neighbourhood income of their patients, and would assert that information bias relating to income is unlikely.

\section{Conclusion}

This study provides important information on how the clinical profiles of patients with diabetes differ based on income. Given that elevated serum lipids, HBA1C and microalbumin to creatinine ratios are all significant predictors of atherosclerosis and mortality [43-45], it is quite plausible that these clinical differences mediate the relationship between income and health outcomes in this population. Whether these differences are influenced by patient, physician, or other factors, remains unclear. However, this study does provide reassurance that within Canada's single payer health care system, prescribing practices do not appear to discriminate against individuals of lower income. In fact, overall mediation use was higher in the lower income groups, appropriately reflecting their higher burden of vascular risk factors.

\section{Competing interests}

All listed authors would like to declare that there were no competing interests involved with this research or the preparation of this manuscript.

\section{Authors' contributions}

DMR conceived the study. DMR and WAG collaborated on the study design. WAG, ALE, PMS, PN and ETL were all involved in the establishment of the database used in this study. DMR led the writing of this manuscript but all listed authors contributed substantially to the editorial process and approved the final manuscript.

\section{Acknowledgements}

We would like to acknowledge the contributions of Drs. Jeff Johnson, Scot Simpson and the investigators of the Alliance for Canadian Health Outcomes Researchers in Diabetes (ACHORD) to this project.

\section{References}

I. National Public Health Survey: Statistics Canada 2006.

2. Banks J, Marmot M, Oldfield Z, Smith JP: Disease and disadvantage in the United States and in England. JAMA 2006, 295(17):2037-45

3. Robbins JM, Vaccarino V, Zhang H, KasI SV: Socioeconomic status and type 2 diabetes in African American and non-Hispanic white women and men: evidence from the Third National Health and Nutrition Examination Survey. Am J Public Health 200I, 9 I(I):76-83.

4. Bachmann MO, Eachus J, Hopper CD, Davey SG, Propper C, Pearson $\mathrm{N}$, et al: Socio-economic inequalities in diabetes complications, control, attitudes and health service use: a cross-sectional study. Diabet Med 2003, 20( II):921-9.

5. Baumann LC, Chang MW, Hoebeke R: Clinical outcomes for lowincome adults with hypertension and diabetes. Nurs Res 2002, $5 I(3): 19 \mid-8$

6. Booth GL, Hux JE: Relationship between avoidable hospitalizations for diabetes mellitus and income level. Arch Intern Med 163(1):101-6. 2003 Jan 13
7. Alter DA, Naylor CD, Austin P, Tu JV: Effects of socioeconomic status on access to invasive cardiac procedures and on mortality after acute myocardial infarction. N Engl J Med 1999, 34 I ( 1 8): I359-67.

8. Pilote L, Joseph L, Belisle P, Penrod J: Universal health insurance coverage does not eliminate inequities in access to cardiac procedures after acute myocardial infarction. Am Heart J 2003, 146(6): 1030-7.

9. Roos LL, Walld R, Uhanova J, Bond R: Physician visits, hospitalizations, and socioeconomic status: ambulatory care sensitive conditions in a canadian setting. Health Serv Res 2005, 40(4): I 167-85.

10. Singh SM, Paszat LF, Li C, He J, Vinden C, Rabeneck L: Association of socioeconomic status and receipt of colorectal cancer investigations: a population-based retrospective cohort study. CMAJ 2004, I 7 I(5):46I-5.

II. Brown LC, Majumdar SR, Newman SC, Johnson JA: History of depression increases risk of type 2 diabetes in younger adults. Diabetes Care 2005, 28(5): 1063-7.

12. Gump BB, Matthews KA, Eberly LE, Chang YF: Depressive symptoms and mortality in men: results from the Multiple Risk Factor Intervention Trial. Stroke 2005, 36(I):98-102.

13. Haas DC, Chaplin WF, Shimbo D, Pickering TG, Burg M, Davidson $\mathrm{KW}$ : Hostility is an independent predictor of recurrent coronary heart disease events in men but not women: results from a population based study. Heart 2005, 9 ( (I2): 1609-I0.

14. Hemingway H, Malik M, Marmot M: Social and psychosocial influences on sudden cardiac death, ventricular arrhythmia and cardiac autonomic function. Eur Heart J 200I, 22(13): I082-I0I.

15. Marmot MG, Shipley MJ, Rose G: Inequalities in death - specific explanations of a general pattern? Lancet I 984, I(8384): I003-6.

16. Marmot MG, Smith GD, Stansfeld S, Patel C, North F, Head J, et al.: Health inequalities among British civil servants: the Whitehall II study. Lancet | 99|, 337(8754): | 387-93.

17. Cohen S, Schwartz JE, Epel E, Kirschbaum C, Sidney S, Seeman T: Socioeconomic status, race, and diurnal cortisol decline in the Coronary Artery Risk Development in Young Adults (CARDIA) Study. Psychosom Med 2006, 68(I):4l-50.

18. Kristenson M, Erikson HR, Sluiter JK, Starke D, Ursin H: Psychobiological mechanism of socio-economic difference in health. Soc Sci Med 2006, 54: I5I I-1522.

19. Kunz-Ebrecht SR, Kirschbaum C, Steptoe A: Work stress, socioeconomic status and neuroendocrine activation over the working day. Soc Sci Med 2006, 58: I523-1530.

20. Gulliford MC, Sedgwick JE, Pearce AJ: Cigarette smoking, health status, socio-economic status and access to health care in diabetes mellitus: a cross-sectional survey. BMC Health Serv Res 2003, 3(1):4.

21. Hemmingsson T, Lundberg I: How far are socioeconomic differences in coronary heart disease hospitalization, all-cause mortality and cardiovascular mortality among adult Swedish males attributable to negative childhood circumstances and behaviour in adolescence? Int J Epidemiol 2005, 34(2):260-7.

22. Langenberg C, Hardy R, Kuh D, Brunner E, Wadsworth M: Central and total obesity in middle aged men and women in relation to lifetime socioeconomic status: evidence from a national birth cohort. J Epidemiol Community Health 2003, 57( 10):816-22.

23. Molnar BE, Gortmaker SL, Bull FC, Buka SL: Unsafe to play? Neighborhood disorder and lack of safety predict reduced physical activity among urban children and adolescents. Am J Health Promot 2004, 18(5):378-86.

24. Winkleby MA, Kraemer HC, Ahn DK, Varady AN: Ethnic and socioeconomic differences in cardiovascular disease risk factors: findings for women from the Third National Health and Nutrition Examination Survey, 1988-1994. JAMA 1998, 280(4):356-62.

25. Winkleby MA, Robinson TN, Sundquist J, Kraemer HC: Ethnic variation in cardiovascular disease risk factors among children and young adults: findings from the Third National Health and Nutrition Examination Survey, 1988-1994. JAMA 1999, 28I(I I): I006-I3.

26. Bobak M, Hertzman C, Skodova Z, Marmot M: Socioeconomic status and cardiovascular risk factors in the Czech Republic. Int J Epidemiol 1999, 28(I):46-52.

27. Larranaga I, Arteagoitia JM, Rodriguez JL, Gonzalez F, Esnaola S, Pinies JA: Socio-economic inequalities in the prevalence of Type 2 
diabetes, cardiovascular risk factors and chronic diabetic complications in the Basque Country, Spain. Diabet Med 2005, 22(8): 1047-53.

28. Rabi DM, Edwards AL, Southern DA, Svenson LW, Sargious PM, Norton P, et al: Association of Socio-Economic Status with Diabetes Prevalence and Utilization of Diabetes Care. BMC Health Serv Res 2006, 6(I): 124

29. Krieger N, Chen JT, Selby JV: Comparing individual-based and household-based measures of social class to assess class inequalities in women's health: a methodological study of 684 US women. J Epidemiol Community Health 1999, 53(10):6 I2-23.

30. Sin DD, Svenson LW, Mann SF: Do are-based markers of poverty accurately measure personal poverty? Canadian Journal of Public Health 2006, 92:184-187.

31. Southern DA, Faris PD, Knudtson ML, Ghali WA: Prognostic relevance of census-derived individual respondent incomes versus household incomes. Can J Public Health 2006, 97(2): I | 4-7.

32. Winkleby MA, Cubbin C: Influence of individual and neighbourhood socioeconomic status on mortality among black, Mexican-American, and white women and men in the United States. J Epidemiol Community Health 2003, 57(6):444-52.

33. Castelli WP, Garrison RJ, Wilson PW, Abbott RD, Kalousdian S, Kannel WB: Incidence of coronary heart disease and lipoprotein cholesterol levels. The Framingham Study 22. JAMA 1986, 256(20):2835-8.

34. Castelli WP: Cholesterol and lipids in the risk of coronary artery disease - the Framingham Heart Study. Can J Cardiol 1988, 4(Suppl A):5A-10A.

35. Wilson PW, Abbott RD, Castelli WP: High density lipoprotein cholesterol and mortality. The Framingham Heart Study. Arteriosclerosis 1988, 8(6):737-4I.

36. Orakzai RH, Orakzai SH, Nasir K, Roguin A, Pimentel I, Carvalho JA, et al.: Association of increased cardiorespiratory fitness with low risk for clustering of metabolic syndrome components in asymptomatic men. Arch Med Res 2006, 37(4):522-8.

37. Schillinger D, Grumbach K, Piette J, Wang F, Osmond D, Daher C, et al:: Association of health literacy with diabetes outcomes. JAMA 2002, 288(4):475-82.

38. Williams MV, Baker DW, Parker RM, Nurss JR: Relationship of functional health literacy to patients' knowledge of their chronic disease. A study of patients with hypertension and diabetes. Arch Intern Med 1998, I 58(2):166-72.

39. The effect of intensive treatment of diabetes on the development and progression of long-term complications in insulindependent diabetes mellitus. The Diabetes Control and Complications Trial Research Group. N Engl J Med 1993, 329(14):977-86.

40. Effect of intensive blood-glucose control with metformin on complications in overweight patients with type 2 diabetes (UKPDS 34). UK Prospective Diabetes Study (UKPDS) Group. Lancet 1998, 352(9|3 I):854-65.

41. Intensive blood-glucose control with sulphonylureas or insulin compared with conventional treatment and risk of complications in patients with type 2 diabetes (UKPDS 33). UK Prospective Diabetes Study (UKPDS) Group. Lancet 1998, 352(9|31):837-53.

42. Tight blood pressure control and risk of macrovascular and microvascular complications in type 2 diabetes: UKPDS 38. UK Prospective Diabetes Study Group. BM] 1998, 3|7(7|60):703-13.

43. MRC/BHF Heart Protection Study of cholesterol lowering with simvastatin in 20,536 high-risk individuals: a randomised placebo-controlled trial. Lancet 2002, 360(9326):7-22.

44. Khaw KT, Wareham N, Bingham S, Luben R, Welch A, Day N: Association of hemoglobin Alc with cardiovascular disease and mortality in adults: the European prospective investigation into cancer in Norfolk. Ann Intern Med 2004, I 4 I (6):4 |3-20.

45. Merjanian R, Budoff M, Adler S, Berman N, Mehrotra R: Coronary artery, aortic wall, and valvular calcification in nondialyzed individuals with type 2 diabetes and renal disease. Kidney Int 2003, 64(I):263-7I.
Publish with Bio Med Central and every scientist can read your work free of charge

"BioMed Central will be the most significant development for disseminating the results of biomedical research in our lifetime. "

Sir Paul Nurse, Cancer Research UK

Your research papers will be:

- available free of charge to the entire biomedical community

- peer reviewed and published immediately upon acceptance

- cited in PubMed and archived on PubMed Central

- yours - you keep the copyright

Submit your manuscript here:

http://www.biomedcentral.com/info/publishing_adv.asp
BioMedcentral 